\title{
A Novel Hierarchical Energy Management System Based on Optimization for Multi-Microgrid
}

\author{
Bilal Naji Alhasnawi and Basil H. Jasim \\ Electrical Engineering Department \\ University of Basrah \\ Basrah, Iraq \\ bilalnaji11@yahoo.com, hanbas632@gmail.com
}

\begin{abstract}
The microgrid vision has come to incorporate various communication technologies, which facilitate residential users to adopt different scheduling schemes in order to manage energy usage with reduced carbon emission. Through this study, we have introduced a novel method for residential load control with energy resources integrated. To this end, an input and optimization algorithm has been employed to control and schedule residential charges for cost savings, consumer inconvenience, and peak-to-average rate savings (PAR) purposes, including real-time electricity costs, energy demand, user expectations, and renewable energy parameters. This paper also provides a Maximum Power Point Tracking (MPPT) technique used to obtain full power from a hybrid power system during the variation of environmental conditions in both photovoltaic stations and batteries. An IEEE 14 bus program was considered to determine the efficiency of the proposed algorithm. This research also aims at developing the role model to determine the behaviors, as a result of a shift in the opening Protocol to the disconnect establishing the power generation island, of distributed energy resources on 14-node IEEE networks. The micro-grid is a simple case for the study of energy flow and smart grid efficiency variables and has dispersed tools. The findings show that the energy management system load collection using the suggested approach improves performance and decreases losses in contrast to previous approaches.
\end{abstract}

Keywords: Optimization; Diesel Generator; Batteries; Converters; Inverters; Microgrid; Utility Grid.

\section{Introduction}

The smart grid is the newest generation of the conventional power system grids which rely on the two-way power flow and information transfer competencies [1]. A traditional grid comprises control centers, power generation, transmission, distribution, and consumers [2]. Presently, with the progression of new digital technologies, like micro processed systems, and developments in power electronics, several applications have been deployed in the smart grid, particularly in the formulation of electronic energy converters and controllers. Of late, academics have made noteworthy contributions which have caused a significant effect on these domains, chiefly aimed at data acquirement, automation, and regulation of micro grids [3]. The micro grids do not merely assimilate the distributed generation with the utility grid in a dependable and tidy manner but also offer greater dependability in its capability to function despite natural phenomena and dynamic distribution grids, consequently causing reduced energy losses in transmission and dissemination and saving the time consumed in building and investment [4][9].

In literature, many reviews directly to different energy management methods. In [10], the author introduced an algorithm based on the linear programming of microgrid power management. This algorithm allowed optimum operation of the generator or controllable and uncontrollable loads. Optimization problems include optimal transmission of generators (diesel) while meeting operational and economic constraints imposed by the purchase and sale of energy for each component (generator, storage system, and load). In [11] analyzed the AC / DC hybrid

Received: March $18^{\text {th }}, 2020$. Accepted: August $5^{\text {rd }}, 2020$

DOI: $10.15676 /$ ijeei.2020.12.3.10 
microgrid AC power management system in an isolated community that employs a photovoltaic system for desalination. The proposed optimization algorithm was relying on mixed-integer nonlinear programming, and objective functionality reduces the daily running cost. In [12] and [13], A power management program was implemented by the author in real-time. The three cases were analyzed with complete, incomplete and exact predictions. On linked and isolated microgrids, the optimization model was tested and there was a significant unbalance between load and generation. In [14], the author introduced energy management for hybrid microgrid photovoltaic / wind turbine / diesel power generators, which are configured with the Gaussian boom particle swarm algorithm. In [15], the authors proposed a centralized energy management program for microgrid service in the Island mode and grid mode. The fuel cell only operates in Island mode when the battery is below $80 \%$. A $60 \%$ threshold is important to ensure stable functionality of grid-connected modes. In [16], the authors proposed the hybrid wind turbine, photovoltaic and battery power integrated microgrid management system. The data storage and control system operates in real time. In [17], the authors proposed an energy management framework for the isolated microgrid, based rules a set of rules to improve MG output through control and surveillance of power generation, loads and storage. The individual occurrence was considered a distribution of the natural probability of failure within the power grid. The goal was to slash the running costs of the microgrid. This covers operating costs for a small generator, wind turbine, batteries, and loads. This analysis decreases the system's costs of capital and power. The presented method has the following disadvantages:

1. Most current models have incomplete plant dynamics because they neglect the effect on the driver, affecting both converter performance and stability.

2. The small-signal model is based on a variety of energy management techniques designs. This means that global stability cannot be assured.

To overcome the aforementioned difficulties, this paper proposes a novel hierarchical energy management system based on optimization for multi-microgrid. The key novel contributions of proposed method in this article can be summarized as follows:

1. Incorporating the uncertainties of loads, resources of distributed renewable, , dissatisfaction cost of inhabitants, aggregator demand control request, and the degradation cost of the battery into the scheduling of smart houses

2. Proposing a two-stage HEMS model that considers optimal day ahead management and an adaptive real-time reliable mechanism to correct the anticipated mistakes,

3. To the best of the authors' knowledge, this paper is the first to propose a home energy management control for both frequency and voltage restoration of a grid connected microgrid and islanded microgrid based on consideration of a complete nonlinear system model, irrespective of parametric disturbances and uncertainties.

4. To reduce the probability of rebound peaks while scheduling, the load has been categorized on the basis of: (1) customer requirements and (2) mathematical models. Then, a multiobjective optimization problem has been formulated and solved by using the optimization algorithm.

\section{Description of Proposed System Model}

Photovoltaic cells and batteries used for energy storage and AC loads are used for the hybrid micro grid evaluated. Once connected, these systems produce a small hybrid micro grid that is connected to an $\mathrm{AC}$ micro grid with low voltage for distribution or isolated mode. Figure 1 displays the hybrid device configuration for the micro grid case delivery. The DC-bus is used to connect the photovoltaic system with the boost transformer. The battery is connected via twoway DC to DC converter to the charging regulator. Batteries are connected via a two-way DC to $\mathrm{DC}$ converter to the DC bus. 


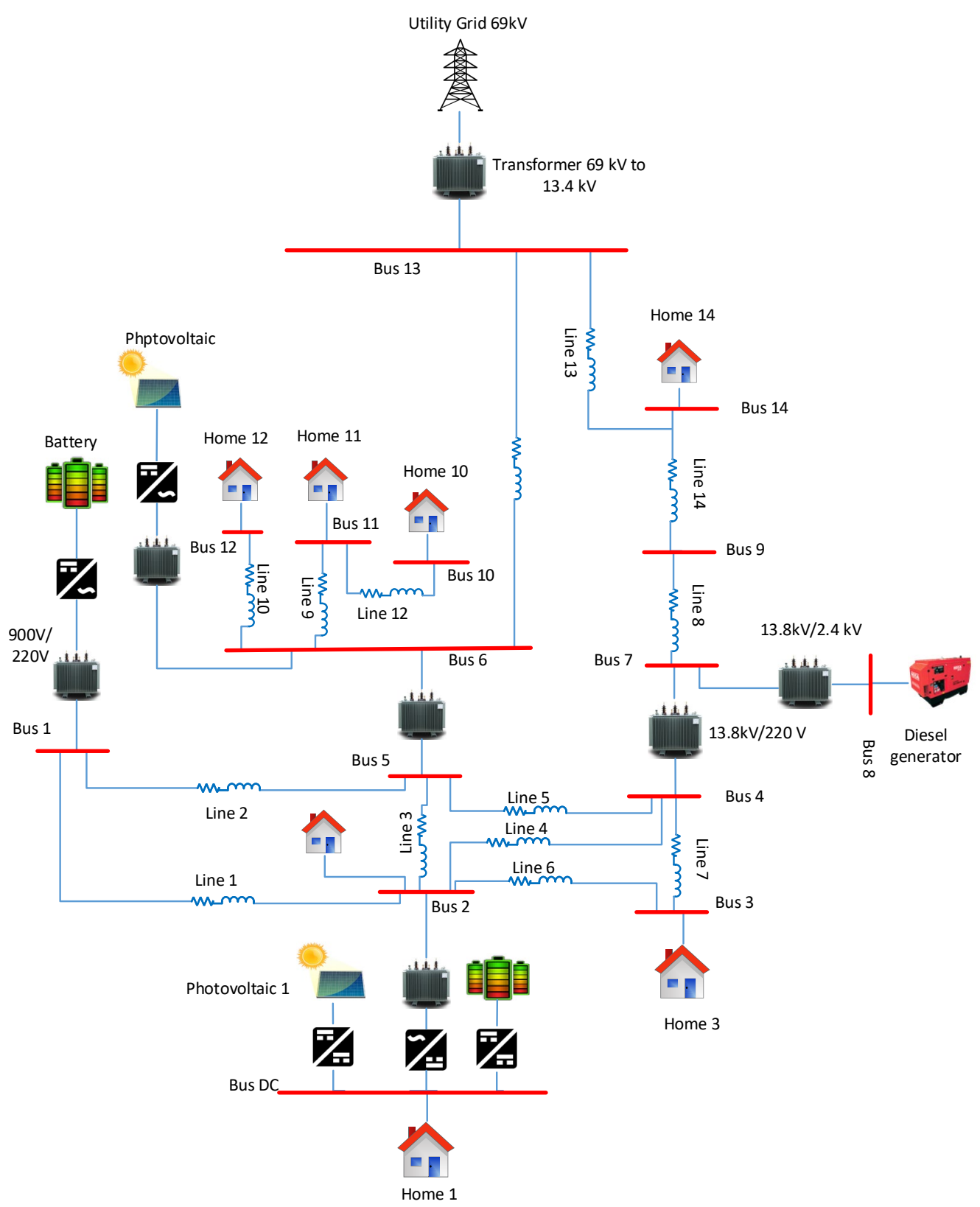

Figure 1. Proposed microgrids system

\section{Distributed Hybrid Energy Generation System}

A. Photovoltaic Modelling

Figure 2 illustrate the equivalent circuit of the photovoltaic [18]. Figure 3 shows voltage and current curve [19-21].

$$
I=I_{p h, \text { cell }}-\underbrace{I_{o, \text { cell }}\left[\exp \left(\left(q\left(V+I R_{-}(s, \text { cell })\right) / a k T\right)-1\right]\right.}_{I_{d, \text { cell }}}-\frac{V+I R_{s, \text { cell }}}{R_{p, \text { cell }}}
$$


Bilal Naji Alhasnawi, et al.

Where, $I_{o, \text { cell }}$ is the saturation current or reversed leakage of the photovoltaic, $k$ is constant of Boltzmann's $1.38 \times 10^{-23} \mathrm{~J} / \mathrm{K} q$ is charge of electron $\left(1.602 \times 10^{-19} \mathrm{C}\right), \quad I_{p h, c e l l}$ is the photocurrent (A) of the photovoltaic, $R_{s, c e l l}$, is series resistance of photovoltaic, $R_{p, c e l l}$ is parallel resistance of photovoltaic.

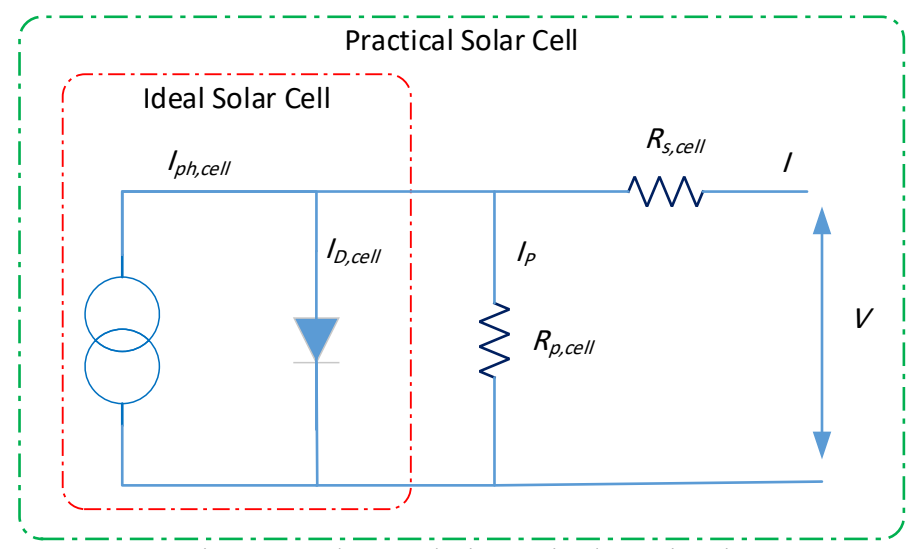

Figure 2. Photovoltaic equivalent circuit
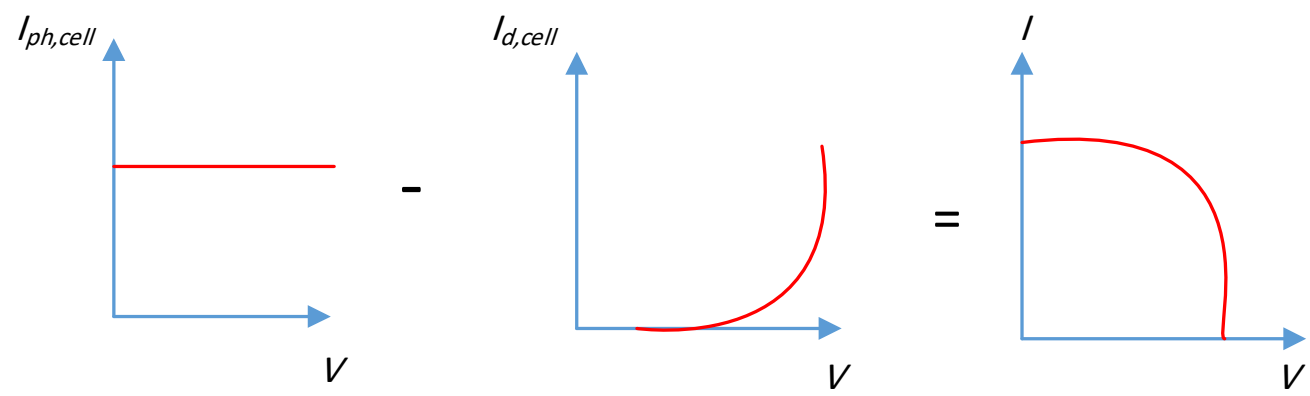

Figure 3. Photovoltaic voltage and current curve

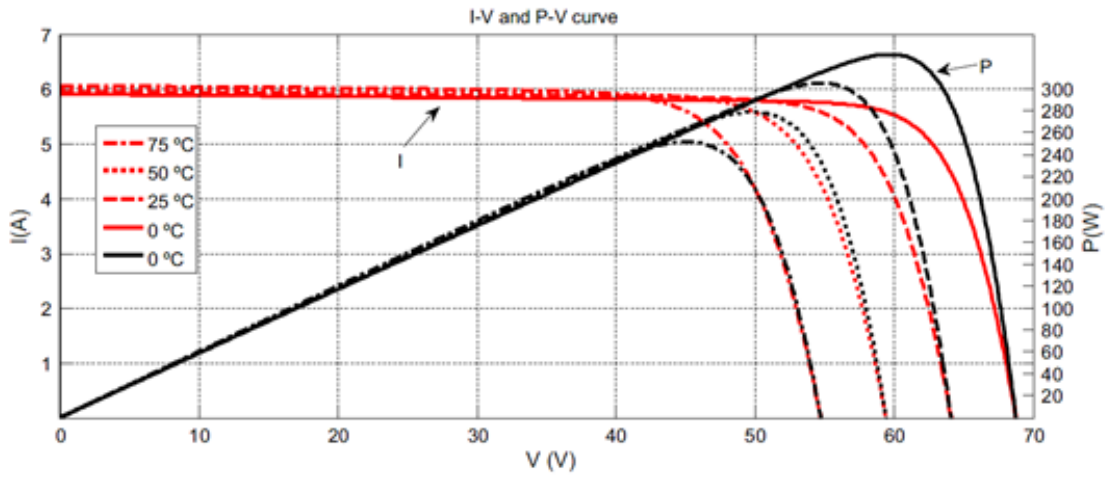

Figure 4 . The photovoltaic voltage and current curves

This corresponds to Equation [22]:

$$
I_{p h}=\frac{G}{G_{n}}\left(I_{p h ; n}+K_{i} \Delta T\right)
$$




$$
\begin{aligned}
& V_{o c}=V_{o c ; n}+K_{v} \Delta T \\
& I_{o}=\frac{I_{s c ; n}+K_{i} \Delta T}{\exp \left(\frac{V_{o c ; n}+K_{v} \Delta T}{a V_{t}}\right)-1}
\end{aligned}
$$

Where $G$ is a measured solar irradiance in $\mathrm{w} / \mathrm{m}^{2} K_{i}$ is temperature coefficient, $I_{p h ; n}$ represents the photocurrentt when it is under the nominal condition (typically a $1000 \mathrm{w} / \mathrm{m}^{2}$ irradiance and $25^{\circ} \mathrm{C}$ temperature $), G_{n}$ is a irradiance $\left(1000 \mathrm{w} / \mathrm{m}^{2}\right), \Delta T$ refers to the difference between the PV cell's actual temperature $(T)$ and a temperature $\left(T_{n}\right)$ measured in ${ }^{\circ} \mathrm{C}, I_{s c ; n}$ is short circuit current under the nominal conditions, [23, 24].

Table 1. Photovoltaic parameter.

\begin{tabular}{|l|c|}
\hline Parameter & Values \\
\hline Modules of series connected & 7 \\
\hline String of Parallel & 1 \\
\hline Maximum current $I_{m p}$ & $5.58(\mathrm{~A})$ \\
\hline Maximum voltage $\left(V_{m p}\right)$ & $54.7(\mathrm{~V})$ \\
\hline Short-circuit current $\left(I_{s c}\right)$ & $5.96(\mathrm{~A})$ \\
\hline Voltage of open circuit $\left(V_{o c}\right)$ & $6.42(\mathrm{~V})$ \\
\hline Temperature coefficient of $\left(I_{s c}\right)$ & $0.061745\left(\% /{ }^{\circ} \mathrm{C}\right)$ \\
\hline Temperature coefficient of $\left(V_{o c}\right)$ & $-0.27269\left(\% /{ }^{\circ} \mathrm{C}\right)$ \\
\hline Shunt resistance $\left(R_{s h}\right)$ & $269.5934 \Omega$ \\
\hline Series resistance $\left(R_{s}\right)$ & $0.37152 \Omega$ \\
\hline Diode saturation curent $I_{o}$ & $6.3 \times 10^{-1}(\mathrm{~A})$ \\
\hline Number of cells & 96 \\
\hline
\end{tabular}

\section{B. Batteries}

Batteries storage system are used to storage additional energy produced by systems for the production of renewable energy. However, if the renewable energy system don't produce sufficient electricity, battery discharge should meet the demand for the load. Type battery is as follows [25-28]:

$$
\begin{aligned}
& S O C_{\text {bat }}=100\left[1-\left(\frac{1}{Q_{b a t}} \times \int_{0}^{t} i_{\text {bat }}(t) d t\right)\right] \\
& B_{A H}=\frac{1}{3600} \int_{0}^{t} i_{b a t}(t) d t
\end{aligned}
$$

Where $i_{\text {bat }}$ represents current of battery, $Q_{b a t}$ refer to maxmum battery capacty(Ah), $S O C_{b a t}$ refer to state of charge of battery $(\%)$,

\section{Loads}

The loads are made up of residential loads. The design of residential loads is based on the resort island's daily non seasonal consumption. Furthermore, simulation of residential load IS performed based on the actual difference in the specified resort island's specific loads profile. 
Table 1. Microgrid load data

\begin{tabular}{|l|c|c|c|c|}
\hline Loads name & $\begin{array}{c}\text { Min-loads } \\
\text { (kVA) }\end{array}$ & $\begin{array}{c}\text { Max-Loads } \\
\text { (KVA) }\end{array}$ & Load type & Power factor \\
\hline Home2 & 13 & 39 & AC & 0.89 \\
\hline Home3 & 10 & 29 & AC & 0.9 \\
\hline Home4 & 14 & 49 & AC & 0.89 \\
\hline Home9 & 100 & 319 & AC & 0.99 \\
\hline Home10 & 239 & 799 & AC & 0.9 \\
\hline Home11 & 119 & 399 & AC & 0.92 \\
\hline Home12 & 239 & 799 & AC & 0.93 \\
\hline Home14 & 479 & 1599 & AC & 0.85 \\
\hline Home1 & 0.7 & 3 & DC & 0.99 \\
\hline
\end{tabular}

\section{Diesel Generator}

Diesel generator provide balance in demand for load and the electricity produced in micro grid. This model consists of a diesel engine, an anticipation system, a control system and a synchronous computer. The governor system and diesel engine models are coupled with two inputs, real (p.u.) speed and the required speed in one unit. The mass production refers to the mechanical power of the diesel engne. The console has similarities to followng transfer functon [21]:

$$
H_{C}=\frac{k\left(1+T_{3} S\right)}{1+T_{1} S+T_{1} T_{2} S}
$$

Where k represents proportonal gain, $\mathrm{T} 3, \mathrm{~T} 1$ and $\mathrm{T} 2$ refer to time constant of regulator (seconds). Below is transfer function of actuator:

$$
H_{a}=\frac{1+T_{4} S}{\left[s\left(1+T_{5} S\right)\left(1+T_{6} S\right)\right]}
$$

Alternatively, the design of diesel engine generators has a time delay that delays the operator's torque output for a specified period. The transfer function below describes the excitation system of the machine [21]:

$$
\frac{V_{f d}}{V_{r o}}=\frac{1}{K_{S}+S T_{e}}
$$

Where $V_{f d}$ represents the exciter voltage, $V_{r o}$ represents the output of the regulator, $K_{s}$ refers to the gain and $T_{e}$ represents the time constant.

\section{E. The Lines Data}

In AC and low-voltage distribution levels standard microgrid distribution lines are common. For the main $13.8-\mathrm{kV}$ network, the unit resistance of line is $0.339 \mathrm{ohm}$ per kilometer, the unit reactance of line is $0.1168 \mathrm{ohm}$ per kilometer and its impedance is $0.41 \mathrm{ohm} /$ kilometers. More details are provided in Table 2 [6].

Table 2. Micro grid line data

\begin{tabular}{|c|c|c|c|}
\hline Line & Distance $(\mathrm{km})$ & $\begin{array}{c}\text { Reactance } \\
\text { (ohm) }\end{array}$ & $\begin{array}{c}\text { Resistors } \\
\text { (ohm) }\end{array}$ \\
\hline 1 & 0.2 & 0.02 & 0.03 \\
\hline 2 & 0.19 & 0.016 & 0.04 \\
\hline 3 & 0.20 & 0.02 & 0.03 \\
\hline 4 & 0.39 & 0.05 & 0.08 \\
\hline 5 & 0.39 & 0.05 & 0.089 \\
\hline 6 & 0.39 & 0.05 & 0.045 \\
\hline
\end{tabular}




\begin{tabular}{|c|c|c|c|}
\hline Line & Distance $(\mathrm{km})$ & $\begin{array}{c}\text { Reactance } \\
(\mathrm{ohm})\end{array}$ & $\begin{array}{c}\text { Resistors } \\
(\mathrm{ohm})\end{array}$ \\
\hline 7 & 0.09 & 0.02 & 0.056 \\
\hline 8 & 1.99 & 0.3 & 0.68 \\
\hline 9 & 5.98 & 0.8 & 4 \\
\hline 10 & 5.98 & 0.80 & 3 \\
\hline 11 & 2.99 & 0.4 & 4 \\
\hline 12 & 5.99 & 0.8 & 3 \\
\hline 13 & 2.5 & 0.4 & 2 \\
\hline 14 & 1.5 & 0.3 & 0.8 \\
\hline
\end{tabular}

\section{Results of Power Flow}

Figure 1 shows hybrid system of micro grid, in which all vector angle value are calculated with a phase locked notch filter adaptive to a loop. Phase lock loop has an auxiliary circuit which gets the phase angle at one stage from the instantaneous voltage waveform. In addition, the angle of the phase current is obtained in the same phase from the instantaneous current wave. Then these two values are subtracted before $\theta$ for all buses is calculated.

At the basic frequency, the power block calculates the reactive power $\left(Q_{i}\right)$ and active power $\left(\mathcal{P}_{i}\right)$ in the basic frequency. The output variables $\left(\mathcal{Q}_{i}\right)$ and $\left(\mathcal{P}_{i}\right)$ are then determined at every fundamentl waveform time, as set out in equation (11), and equation (12) [6]:

$$
\begin{aligned}
& \mathcal{Q}_{i}=\frac{1}{2} \times \sin \left(\theta_{i}\right) \times \mathcal{V}_{i} \times \mathcal{J}_{i} \\
& \mathcal{P}_{i}=\frac{1}{2} \times \cos \left(\theta_{i}\right) \times \mathcal{V}_{i} \times \mathcal{J}_{i}
\end{aligned}
$$

Where:

$\mathcal{Q}_{i}$ is one phase reactive power, $\mathcal{P}_{i}$ is one phase active power, $\mathcal{J}_{i}$ is per-phase current, $\mathcal{V}_{i}$ is perphase voltage, $\theta_{i}$ is difference between current and voltage.

This section also demonstrates proposed system's simulation result. Hybrid microgrids are responsible for stabilising the operations in stable condition under minimum and maximum demand scenario. Simulink furnished per phase calculations. However, the active and reactive power value presented in Table 3 and Table 4 represent sum of per phase power, or in other words, the sums for the three phase active and reactive power,. For any load bus, $\mathcal{P}_{1}$ and $\mathcal{Q}_{1}$ are presented, while $\mathcal{P}_{g}$ and $\mathcal{Q}_{g}$ are presented for any generator bus. Lastly, for any transfer bus, $\mathcal{P}_{\text {transfer }}$ and $\mathcal{Q}_{\text {transfer }}$ are given.

Table 3. Result of loads at minimum demand

\begin{tabular}{|c|c|c|c|c|c|c|c|c|}
\hline Bus & Angle(degree) & $\mathrm{V}$ & $\mathcal{Q}_{g}$ & $\mathcal{P}_{g}$ & $\mathcal{Q}_{1}$ & $\mathcal{P}_{1}$ & $\mathcal{Q}_{\text {transfer }}$ & $\mathcal{P}_{\text {transfer }}$ \\
\hline 1 & -29 & 0.91 & 14 & 30 & & & & \\
\hline 2 & -29.9 & 0.94 & & & & & 6 & 15 \\
\hline 3 & -32 & 0.92 & & & 12 & 19 & 15 & 21 \\
\hline 4 & -30 & 0.93 & & & & & 26 & 49.9 \\
\hline 5 & -34 & 0.95 & & & & & 25 & 49 \\
\hline 6 & -32 & 0.94 & & & & & 350 & 480 \\
\hline 7 & -29 & 0.96 & & & & & 90 & 90 \\
\hline 8 & -65 & 0.96 & 50 & 140 & & & & \\
\hline 9 & -29 & 0.93 & & & 0.70 & 109 & & \\
\hline 10 & -29 & 0.93 & & & 140 & 190 & & \\
\hline 11 & -29 & 0.99 & & & 70 & 89 & & \\
\hline 12 & -29 & 0.89 & & & 140 & 190 & & \\
\hline 13 & -29 & 0.93 & 70 & 89 & & & & \\
\hline 14 & -29 & 0.91 & & & 280 & 380 & 79 & 19 \\
\hline
\end{tabular}


Table 4. Result of loads at maximum demand

\begin{tabular}{|c|c|c|c|c|c|c|c|c|}
\hline Bus & Angle(degree) & $\mathrm{V}$ & $\mathcal{Q}_{g}$ & $\mathcal{P}_{g}$ & $\mathcal{Q}_{1}$ & $\mathcal{P}_{1}$ & $\mathcal{Q}_{\text {transfer }}$ & $\mathcal{P}_{\text {transfer }}$ \\
\hline 1 & -30.1 & 0.89 & 29.99 & 45 & & & & \\
\hline 2 & -29.5 & 0.90 & & & & & 5 & 39 \\
\hline 3 & -30.3 & 0.91 & & & 41 & 65 & 42 & 59 \\
\hline 4 & -32.4 & 0.92 & & & & & 90 & 125 \\
\hline 5 & -30.3 & 0.93 & & & & & 60 & 37 \\
\hline 6 & -32.2 & 0.94 & & & & & 1080 & 790 \\
\hline 7 & -31.1 & 0.90 & & & & & 350 & 560 \\
\hline 8 & -59.99 & 0.91 & 430 & 680 & & & & \\
\hline 9 & -29.9 & 0.93 & & & 37 & 330 & & \\
\hline 10 & -30.1 & 0.91 & & & 430 & 580 & & \\
\hline 11 & -29.99 & 0.92 & & & 220 & 280 & & \\
\hline 12 & -29.8 & 0.91 & & & 450 & 580 & & \\
\hline 13 & -29.7 & 0.89 & 1670 & 1820 & & & & \\
\hline 14 & -29.3 & 0.92 & & & 90 & 120 & 350 & 230 \\
\hline
\end{tabular}

\section{Proposed System Analysis}

Two analytical schemes are established to compute metrics for describing the primary cases concerning future studies focusing on optimisation and compensation. figure 5 depicts the characteristics of daily demand for the suggested hybrid microgrid system. The curve is obtained by computing total hourly demand specific to every load defined by the model, which includes the critical load components, namely commercial and industrial. Load modelling was based on fixed impedance; therefore, the nominal power and actual power used differ slightly because of the voltage drop created in the system. As illustrate in figure 5, system's minimum demand is only $30 \%$ of the maximum demand. Active and reactive power demand in system is assumed to have a similar relationship. The minimum demand situation must be used to ascertain the capacity and placement of the compensation mechanism. Interacting compensating components may cause an overvoltage scenario in the system. Referring to figure 6 , it can be observed that there is maximum demand at 11:00, which is also the time at which solar radiation, and, therefore, solar power production is also maximised. The increased power demand witnessed at this time is caused by the combination of industrial and domestic loads [6].

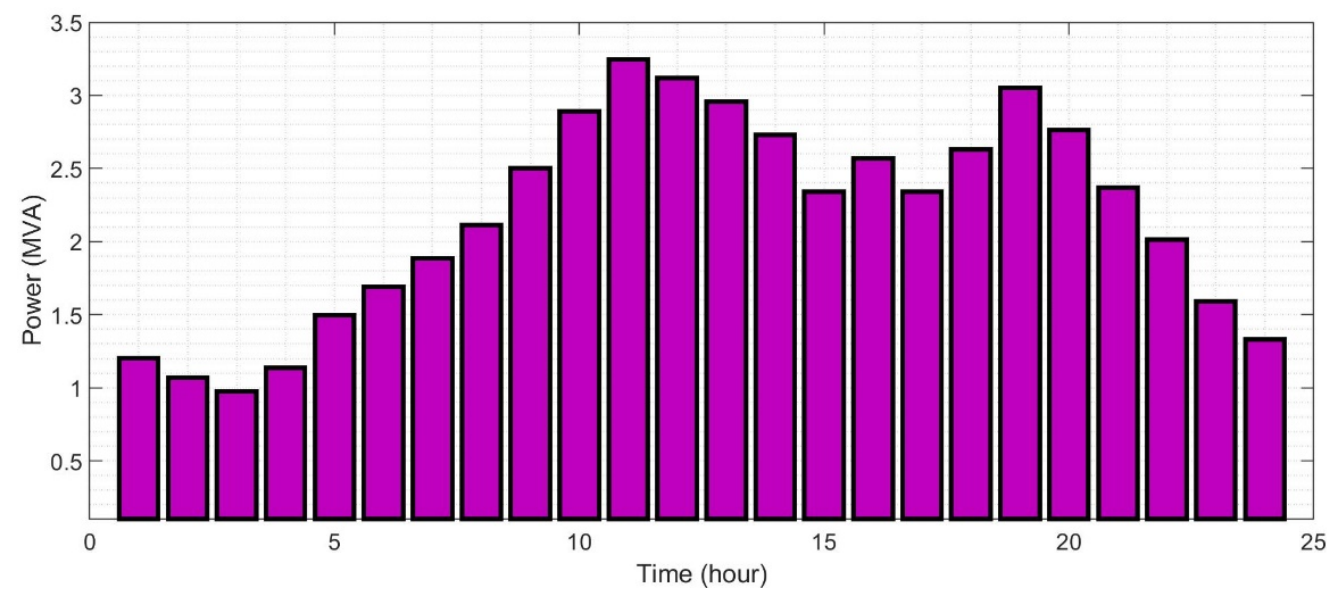

Figure 5. The curve of demand for one day 


\section{Analysis of Voltage Profile}

Figure 6 depicts the voltage profile determined for analysing the maximum load energy scenario, while figure 7 depicts the voltage profile for minimum load capacity. The system operates under single-phase loading leading to unbalanced loads, thereby warranting a voltage profile analysis. In both situations, the voltage profile adheres to the appropriate operating standards. Nevertheless, as highlighted in Figure 6, when demand is at its maximum level, low voltage grid $(220 \mathrm{~V})$ buses 2 and 3 witness a noteworthy drop in voltage. Voltage profile quality is specified using indicators depicted in Figures 6 and 7. Equations (13) and (14) specify the calculation for average voltage deviation for the system [6].

$$
\text { Voltage Average Deviation }=\frac{1}{n} \times \sum_{i=1}^{n}\left|\mathcal{V}_{d i}-\mathcal{V}_{i}\right|
$$

This function represents the maximum voltage deviation in the system.

$$
\text { Maximum Voltage Deviation }=\max _{1 \leq i \leq n}\left[\left|\mathcal{V}_{d i}-\mathcal{V}_{i}\right|\right]
$$

$\mathcal{V}_{d i}$ is the desired voltage, and $\mathcal{V}_{i}$ is the bus voltage, and $\mathrm{n}$ is the buses number.

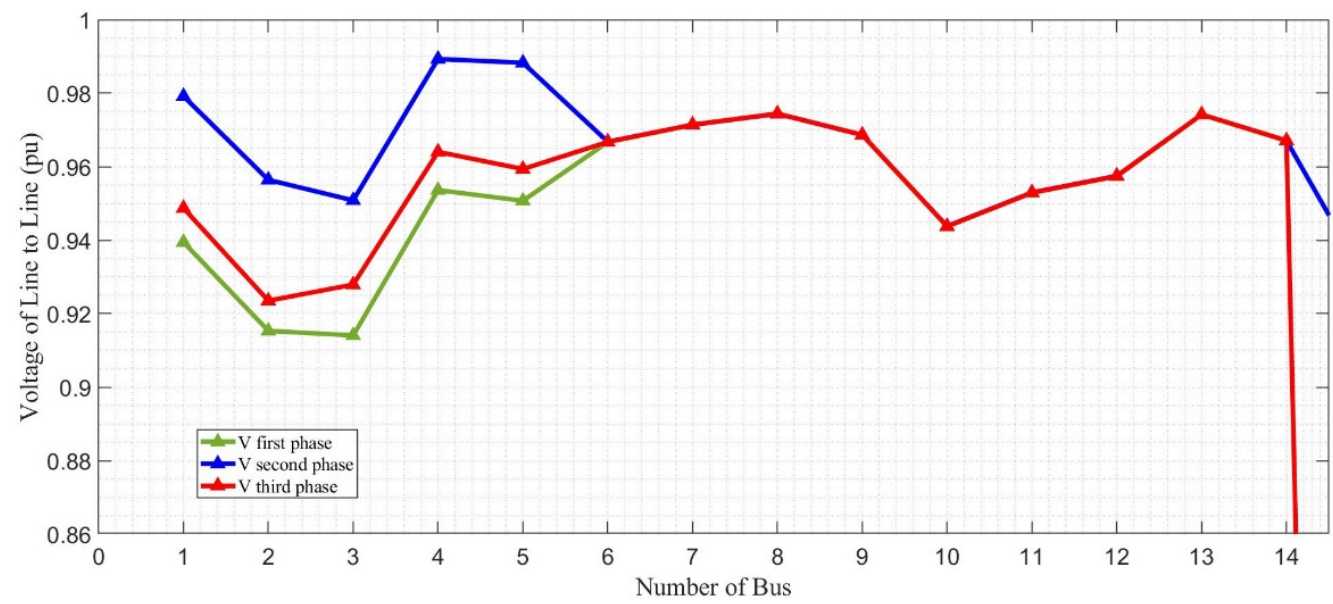

Figure 6. Maximum demand voltage

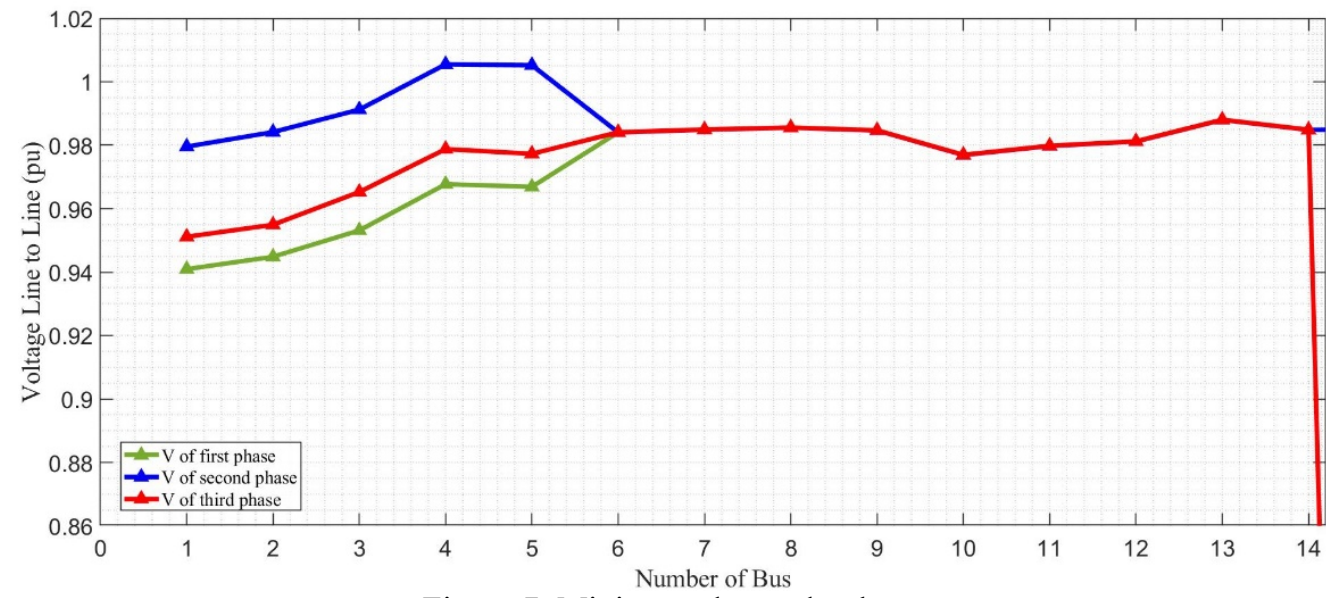

Figure 7. Minimum demand voltage

\section{Buss Active Power-Balance}

Figures 8 and 9 highlight the power production and consumption characteristics (in kVA) for every system bus, including the power level $(\mathrm{kW})$ at the DC bus. A positive value on the graph 
indicates the power (load) drawn by the bus. Bus 14 has a negative power level; hence, there is a transfer to bus 14 from bus 9 acting as a source of power concerning the diesel generation. Tables 3 and 4 describe these situations along with the residual negative capacity for generation specific to the bus. Considering the maximum demand situation in figure 8 , there are six bus (1, $2,6,7,13$, and the DC bus) that generate power. Figure 9 depicts the balance of power in the system concerning the minimum demand situation. At maximum demand, the power level for every bus decreases. For this situation, the characteristics of distributed generation are specified, leaving diesel generator 8 connected to the bus. At the same time, the remaining inactive power contribution is made through bus 13 connected to the grid.

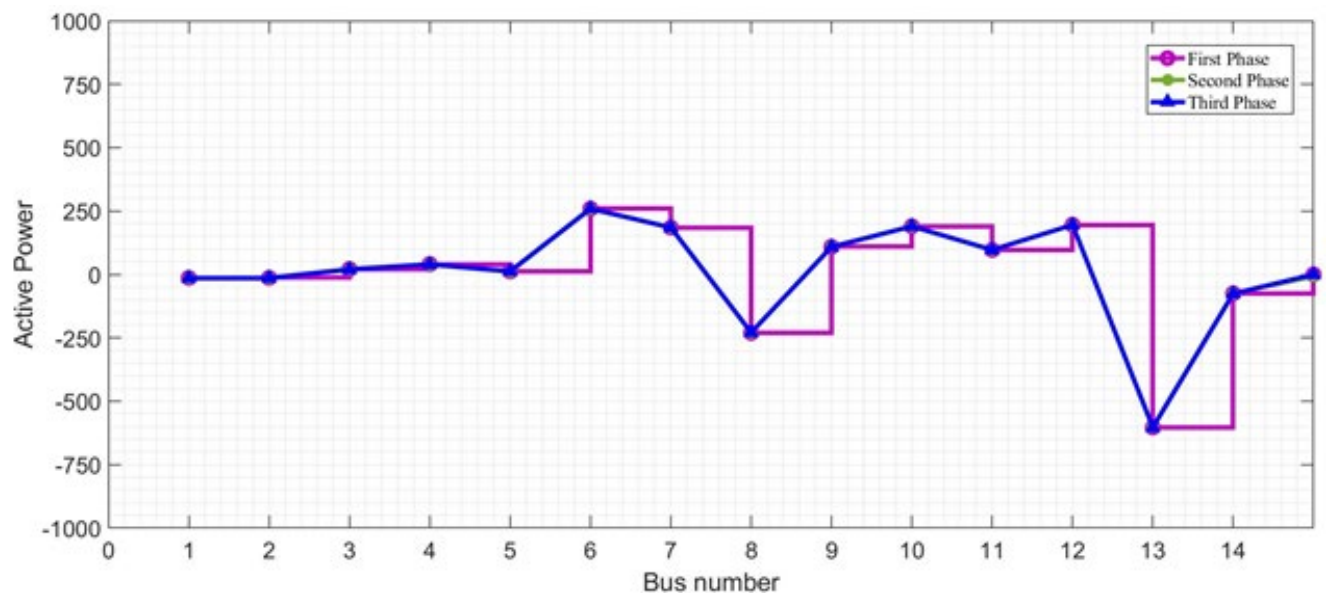

Figure 8. Maximum power balance

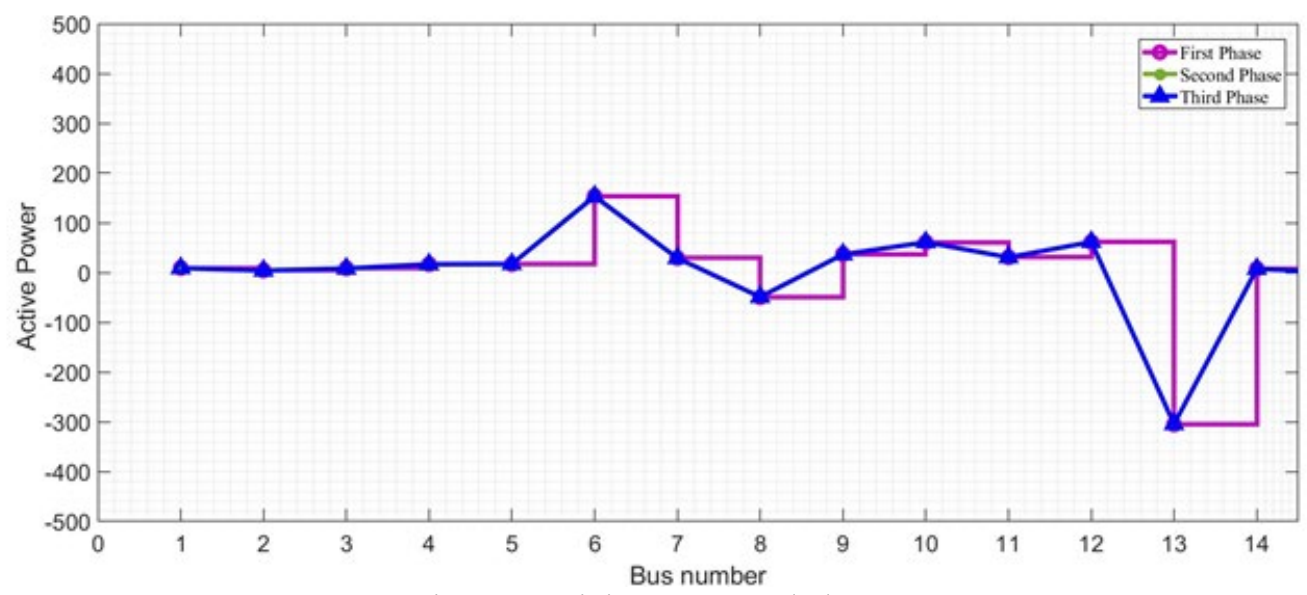

Figure 9. Minimum power balance

\section{Analysis Reactive-Power Balance}

Figures 10 and 11 highlight system characteristics at the maximum and minimum demand levels, respectively. Bus-specific voltage profiles, reactive power balances, changes in voltage phase angles, are depicted in the abovementioned figures. In both situations, it can be observed that there is an association between reactive injection and the voltage increment at the bus, where the present power generation compensates for reactive powers. The reactive powers of systems is observed using Bus8 having diesel generators, and Bus13 having external reactive power. Nevertheless, as depicted in figure 10, the maximum demand situation indicates the transfer of reactive power to buses 9 and 14 . 
Specific to this scenario, the power flow direction indicates negative power at these buses. Tables 3 and 4 provide details specific to these situations. The analysis of reactive power compensation requires these crucial scenarios as the starting points to obtain voltage optimisation. Concerning maximum demand, the compensation values can be validated using an analysis of the contributions during minimum demand. Figure 11 highlights the voltage characteristics concerning the specified case. Values are appropriate, and for certain buses, they exceed one p.u. In such cases, analyses should be performed during reactive power injection increase to optimise maximum demand situations.

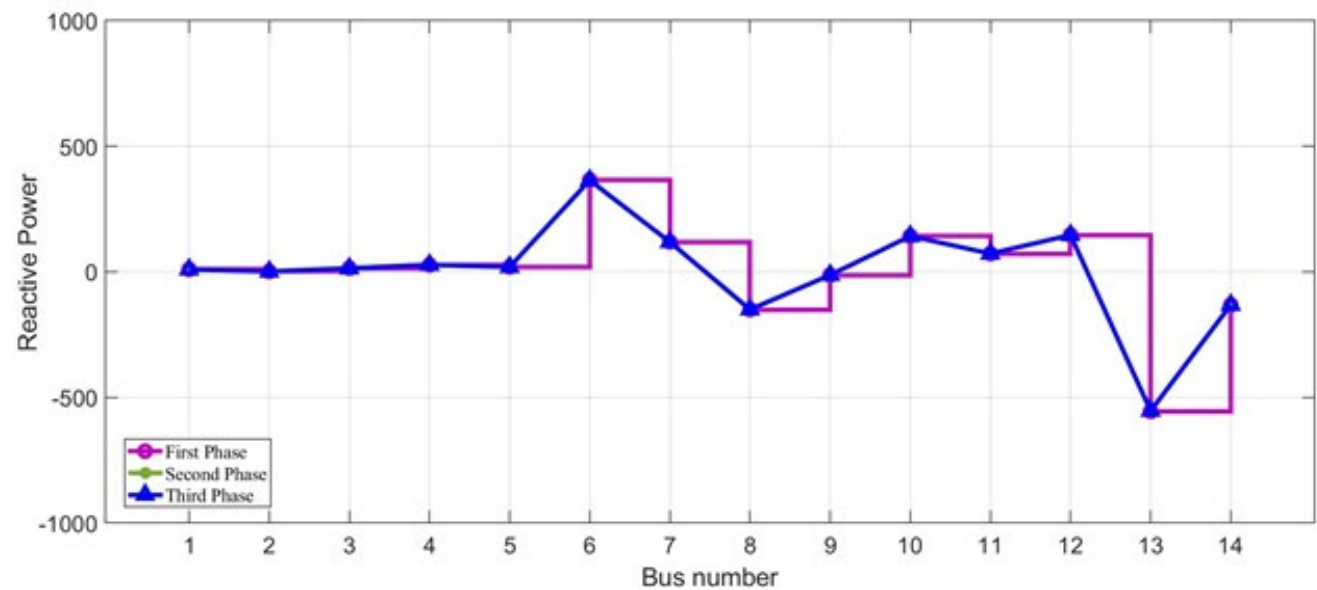

(a)

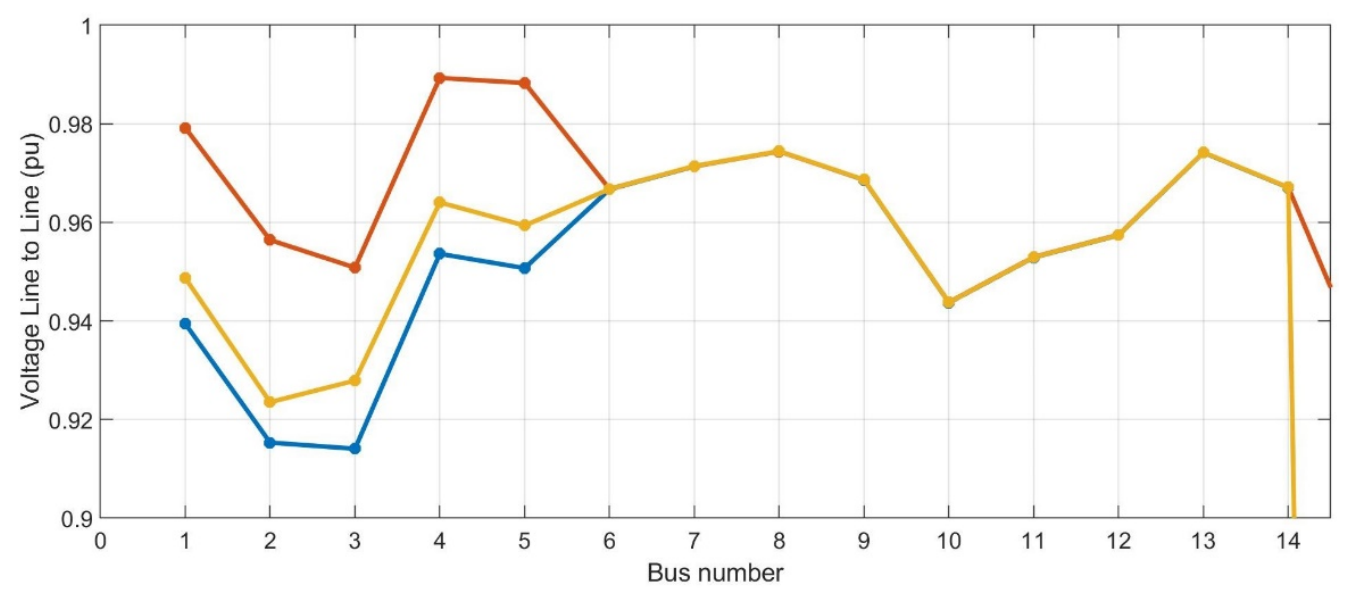

(b)

Figure10. (a) The reactive power balance at maximum demand (b) The voltage at maximum demand 


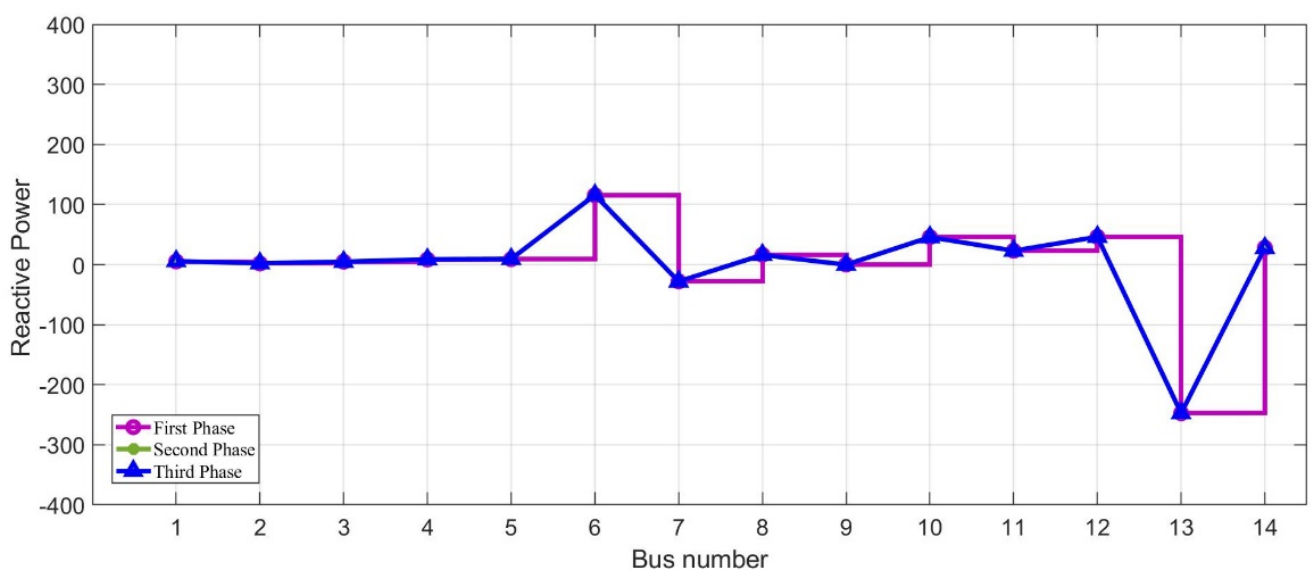

(a)

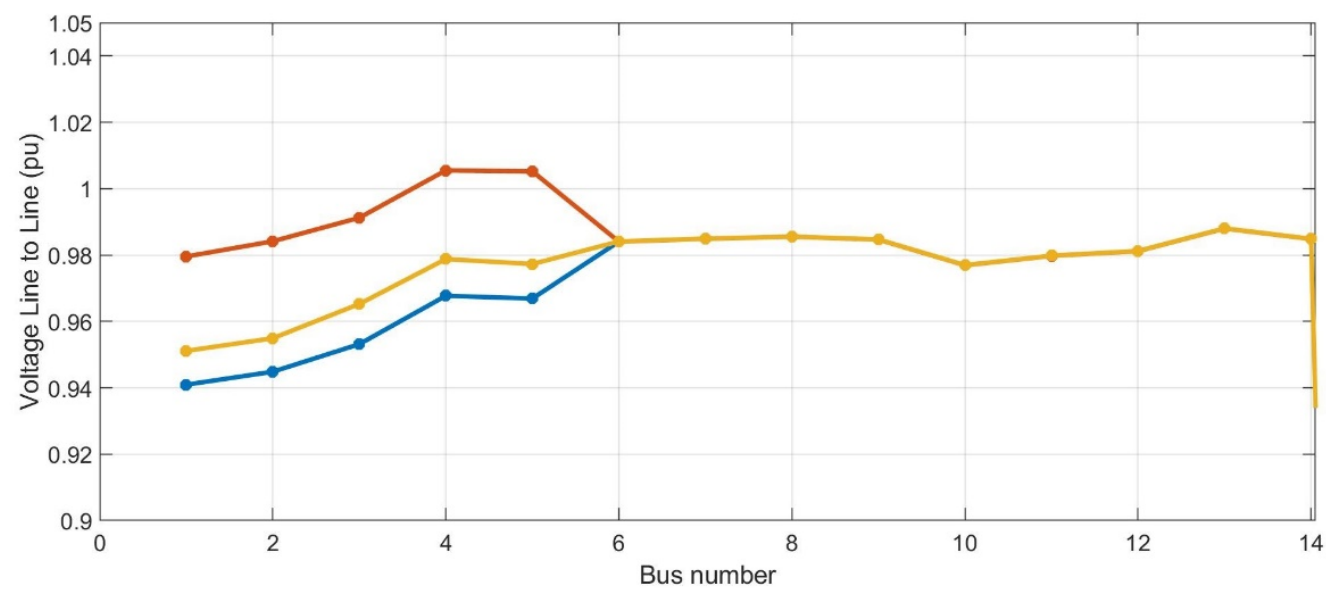

(b)

Figure 11. (a) The reactive power balance at minimum demand

(b) The voltage at minimum demand

\section{The Power Losses for Lines}

The active powers loss for the system was computed under both balanced and unbalanced currents. Equation (15) specifies the power loss concerning a State of Charge (SoC) using first line and second line [6]:

$$
\mathcal{P}_{a, b}=\left(\sum_{i=1}^{n}\left|\mathcal{J}_{i, a, b}\right|^{2}\right) \times\left(\mathcal{R}_{n}+\mathcal{R}_{\ell}\right)
$$

where:

$n$ is number of phases of the system in line $b$.

$\mathcal{J}_{i, a, b}$ is current in one phase

$\mathcal{R}_{n}, \mathcal{R}_{\ell}$ are resistors of one phase,

Figures 12 and 13 depict the phase loss for every line when the system is in minimum and maximum demand situations. It can be observed from the figures that the maximum loss occurs during low-voltage on the grid carrier feed line. Concerning every phase, the highest power loss of approximately $9.9 \mathrm{~kW}$ is present on line 7 (responsible for connecting buses 3 and 4); nevertheless, there is less distance. Figures 12 and 13 depict the active power losses happening 
on every phase under unbalanced loading. Such an imbalance in load is because of the lowvoltage grid supplying single-phase loads. Figure 13 highlights that the maximum loss per phase is limited to $1.4 \mathrm{~kW}$. This level is significantly less compared to the maximum demands loss specific to every phase.

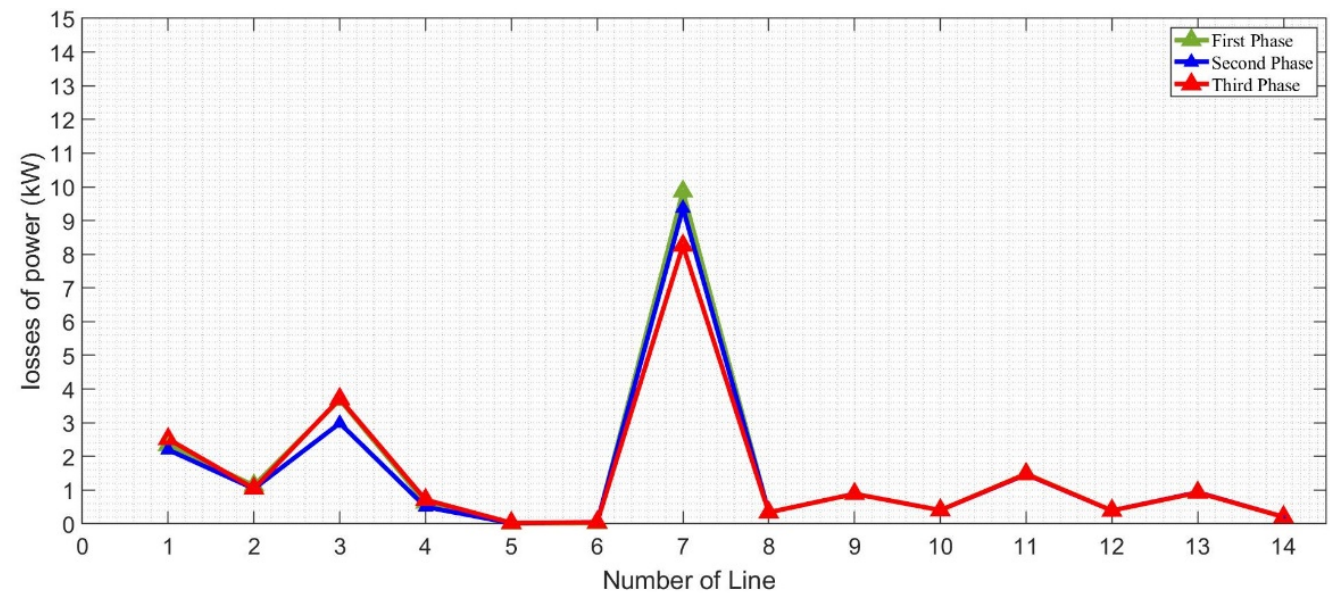

Figure 12. Maximum demand power losses per phase

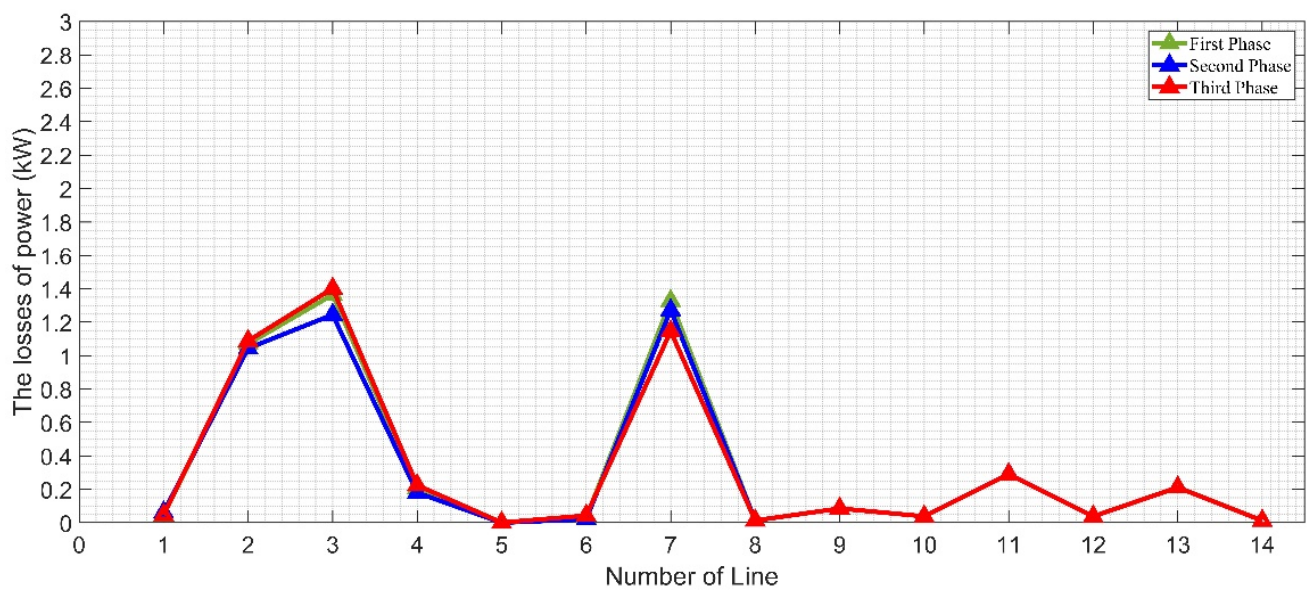

Figure 13. Minimum demand power losses per phase

\section{Energy Management Model}

A two-stage hierarchical framework for energy management is proposed, in keeping with the hierarchical control system of the microgrid group. The lower energy management system concentrates on microgrid level and minimizes microgrid operating costs. The control objects, including generators, energy store systems and loads, are all microgrid tools. Photovoltaic typically works at full power output to effectively use renewable energy. The key controlling objects of the Energy Management System (EMS) are also controllable composed of a micro source (MS), an energy storage network and a controllable load (CL). The lower stage of the EMS will include the power references and unit startup / shutdown plan for the CMS, the power references for charging / discharging for the ESS, the CL change or reduction programmer: the RES (Res) and energy specifications for Renewable Energy Sources ( RES). Therefore, the sharing of power between the MG and the upstream grid has to be determined. The real-time state of responsibility (SoC) of the ESS needs to be calculated in the decision-making process to achieve relevant results. 
The energy management program at high level is responsible for the management of MGs and microgrid community level device (MCLD). The EMS seeks to keep the whole microgrid group (MGC) operating costs minimized. As in the lower EMS level, the high-level EMS may include MCLD operating instructions including power references, start-up, and shut-down systems, and power references for charging or unloading.

\section{A. Day-Ahead Management}

The Home Energy Management Systems (HEMS) algorithm generally resolves the optimal operating plan for Distributed Energy Resources (DER) and home appliances. This study considers diesel generators, photovoltaic units, and batteries as DERs. The household appliances are classified into two classes to describe the customer's changed usage pattern; unaccompanied (critical) loads and controllable. An uncheckable load such as a TV or lighting cannot be planned by HEMS. Appliances whose HEMS controls the operation are included in the controlled load. We separate controllable loads into constantly controllable loads and moves loads. This study describes the constantly controllable shift capabilities and critical loads of the Heating, Ventilation and Air Conditioning (HVAC), the water heater and must-run services. With view of consumer comfort level and power prices, the HEMS controls all controllable (all constantly controllable and shift-free) devices and the power. The optimal load pattern decided by the operating agent should also be compiled.

\section{B. Implementation of Linear Programming Method to Solve the EMS Problem}

This paper provides the solution of this EMS problem with a linear programming model algorithm designed to optimize the utility of the demand cluster with regard to a set of constraints, such as daily minimum energy usage, maximum or minimum hourly load rates, energy storage limits and electricity available from the principal grid and the distributed energy resources.

The model proposed is developed with the following linear objective function as a linear program optimization problem:

$$
C_{\text {tot }}=\sum_{k=0}^{N} C_{\text {grid }}(k) \cdot E_{\text {grid }}(k)
$$

The first phase determines the reserves for energy and control of each MG and the energy and reserves exchanged among the MGs. In this stage, the following limitations should be taken into account:

$$
\begin{aligned}
& E_{\text {batt }}(k)=E_{\text {batt }}(k-1)+P_{\text {batt }}(k) \Delta T \\
& P_{p v}(k)+P_{\text {grid }}(k)+P_{\text {batt }}(k)=P_{\text {load }}(k) \\
& \min _{x} . f^{T} x \text { such that }\left\{\begin{array}{c}
A \cdot x \leq b \\
A_{e q} \cdot x=b_{e q}
\end{array}\right\} \\
& x=\left[P_{\text {grid }}(1: N) P_{\text {batt }}(1: N) E_{\text {batt }}(1: N)\right]^{T} \\
& \underbrace{\left[\begin{array}{lll}
I_{N \times N} & I_{N \times N} & 0_{N \times N} \\
O_{N \times N} & Y_{N \times N} & \Phi_{N \times N}
\end{array}\right]}_{\text {Aeq }} \mathrm{X}=\underbrace{\left[\begin{array}{c}
P_{\text {load }}(1: N)-P_{p v}(1: N) \\
E_{\text {batt }}(1) \\
0_{N-1}
\end{array}\right]}_{\text {beq }} \\
& \Upsilon_{3 \times 3}=\left[\begin{array}{ccc}
0 & 0 & 0 \\
\Delta T & 0 & 0 \\
0 & \Delta T & 0
\end{array}\right] \\
& \Phi_{3 \times 3}=\left[\begin{array}{ccc}
1 & 0 & 0 \\
-1 & 1 & 0 \\
0 & -1 & 1
\end{array}\right]
\end{aligned}
$$




$$
\underbrace{\left[\begin{array}{ccc}
O_{N \times N} & I_{N \times N} & O_{N \times N} \\
O_{N \times N} & -I_{N \times N} & O_{N \times N} \\
O_{N \times N} & O_{N \times N} & I_{N \times N} \\
O_{N \times N} & O_{N \times N} & -I_{N \times N}
\end{array}\right]}_{A} X \geq \underbrace{\left[\begin{array}{c}
P_{\max } \\
-P_{\min } \\
E_{\max } \\
-E_{\min }
\end{array}\right]}_{b}
$$

The community energy management system with photovoltaic and battery:

$\operatorname{minimize} \sum_{t=1}^{N} \delta c_{t} G_{t}-w E_{N}+\sum_{t=1}^{N-1} g_{t}$

Subject to:

$$
\begin{gathered}
E_{1}=E_{\text {initial }} \\
E_{\mathrm{t}+1}=E_{t}-\delta B_{t} \\
S_{\mathrm{t}}+G_{t}+B_{t}=d_{t} \\
G_{\mathrm{t}+1}-G_{t} \leq g_{t} \\
l_{B} \leq B_{t} \leq u_{B} \\
l_{E} \leq E_{t} \leq u_{E}
\end{gathered}
$$

Where $G_{t}$ the power from grid is, $B_{t}$ is the power from battery, $E_{t}$ is the stored energy, $g_{t}$ is the change in power from grid

\section{Simulation Results of Optimization Method}

As shown in Figure 1, the proposed model is simulated on a radial test network with three microgrids. A 24-hour scheduling horizon tests the mathematical problem. In an isolated structure, the interconnected microgrids are operated which are separated from the upstream grid. All micro grids include DGs, RES modules, as well as active and reactive loads and demand response programs in some selected buses. Each microgrid includes RES modules. The details on the microgrid 's total load and demand response system is shown in table 1.

Since the proposed method confrontations with a roughly similar data-driven approach to uncertainty in stochastic confrontation, it was chosen to calculate HEMS efficiency using the Heuristics algorithm. The analysis is summarised in Figure 14, Figure 15, Figure 16 and Figure 17 between several research studies on energy scheduling of the micro grids.

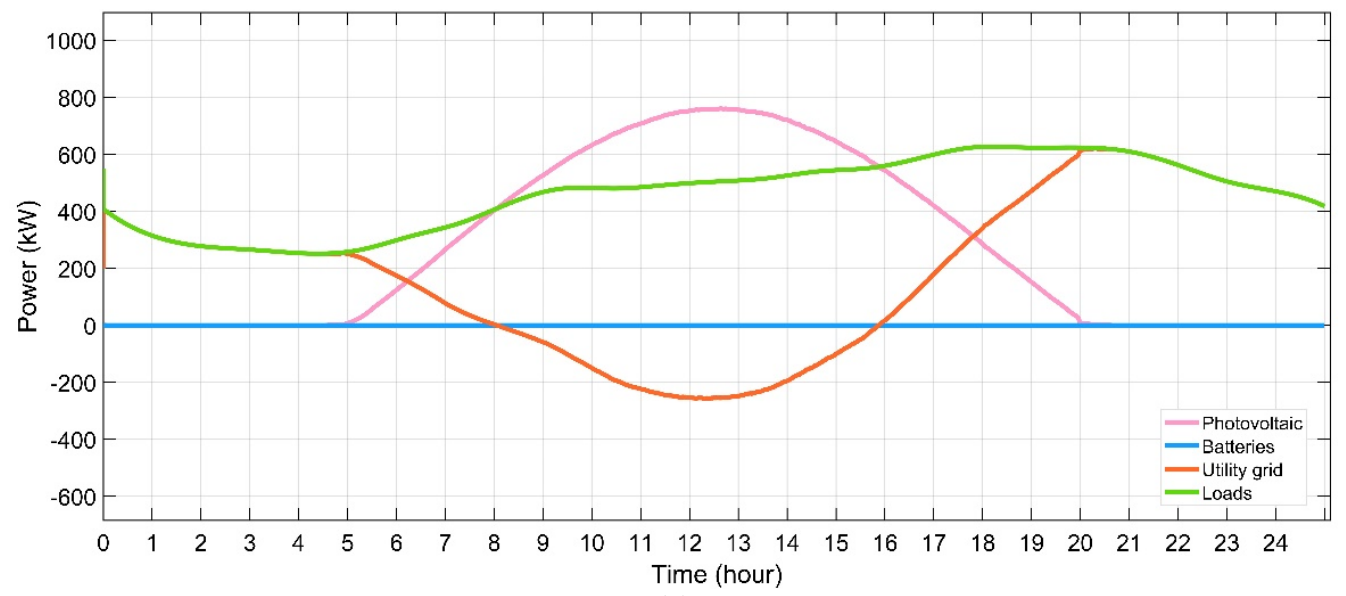

(a) 
Bilal Naji Alhasnawi, et al.

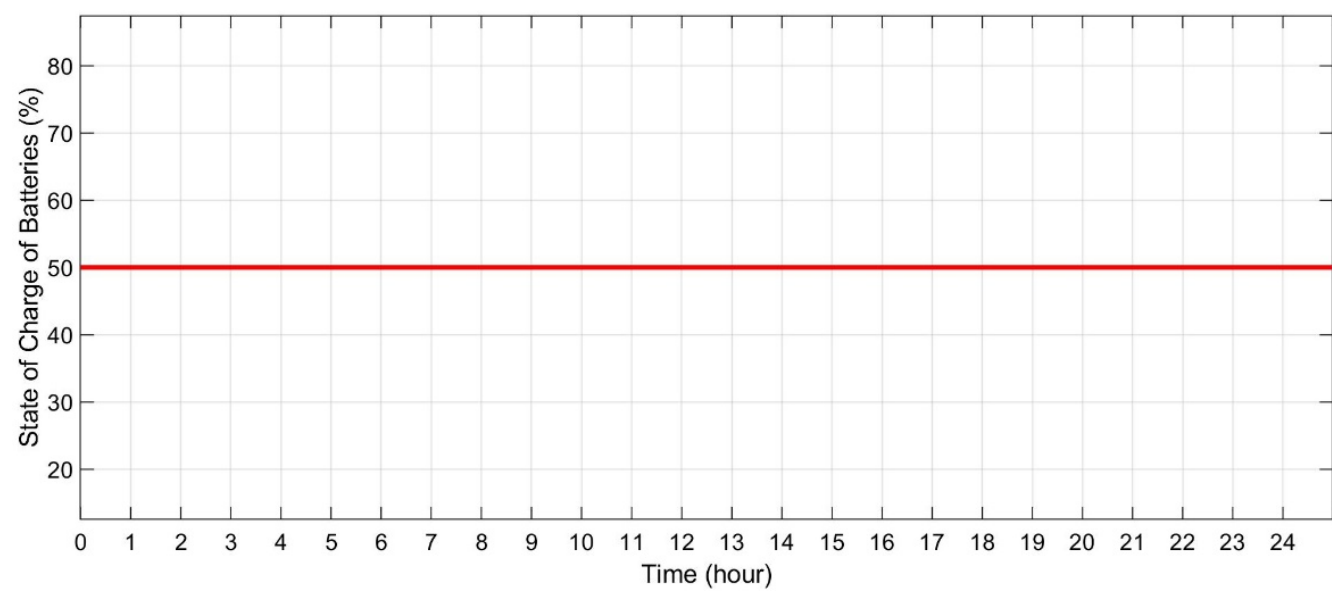

(b)

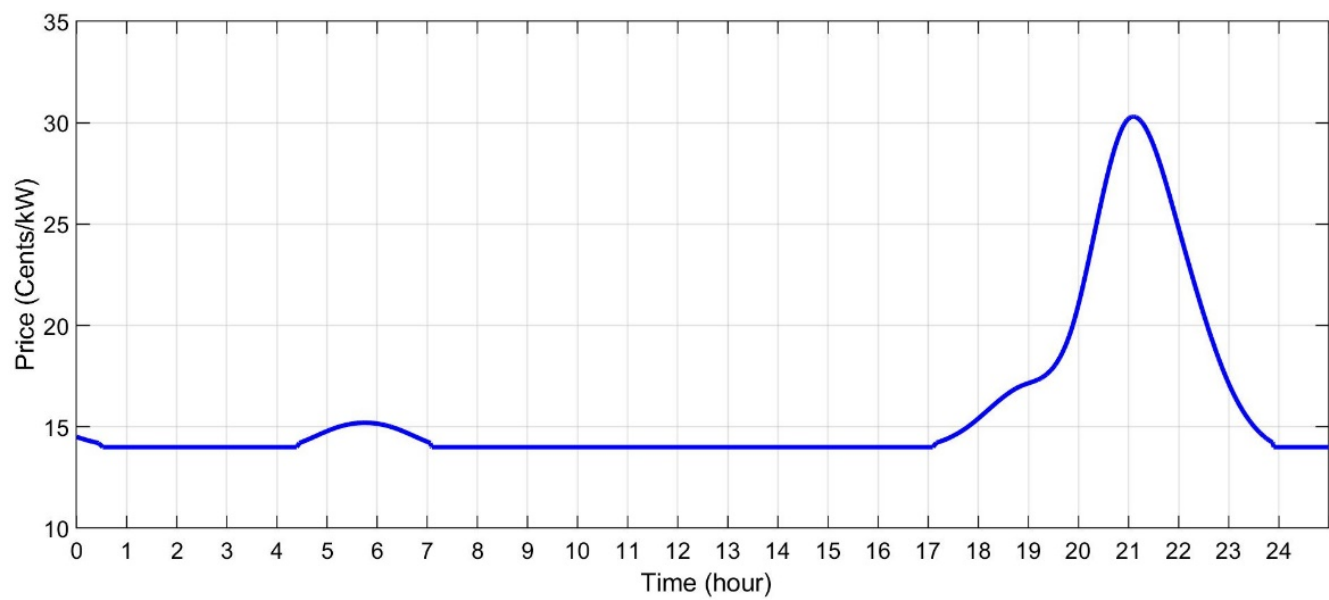

(c)

Figure 14. Heuristics method, (a) power of renewable energy sources,

(b) SoC of energy storage system, (c) The price

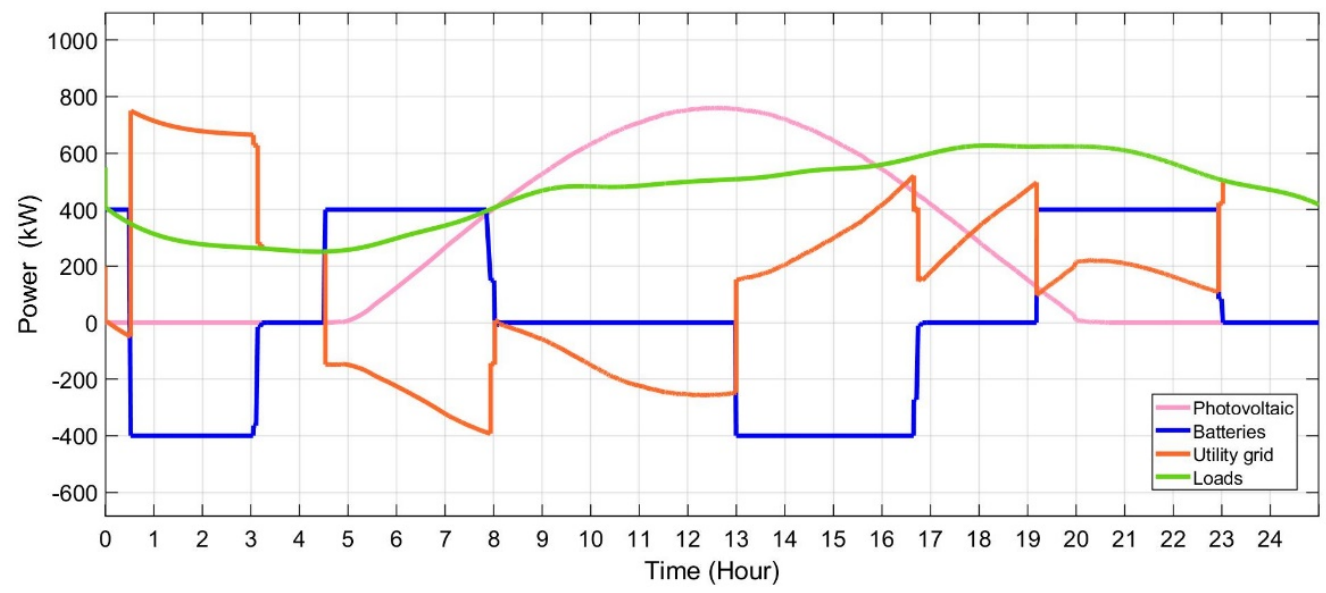

(a) 


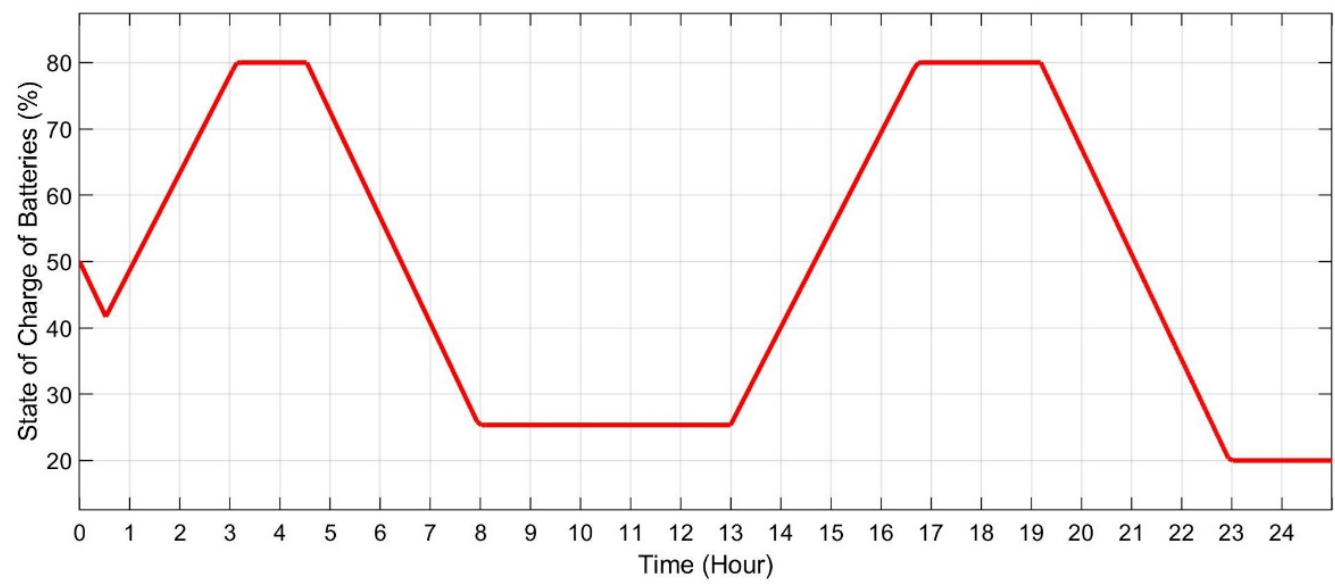

(b)

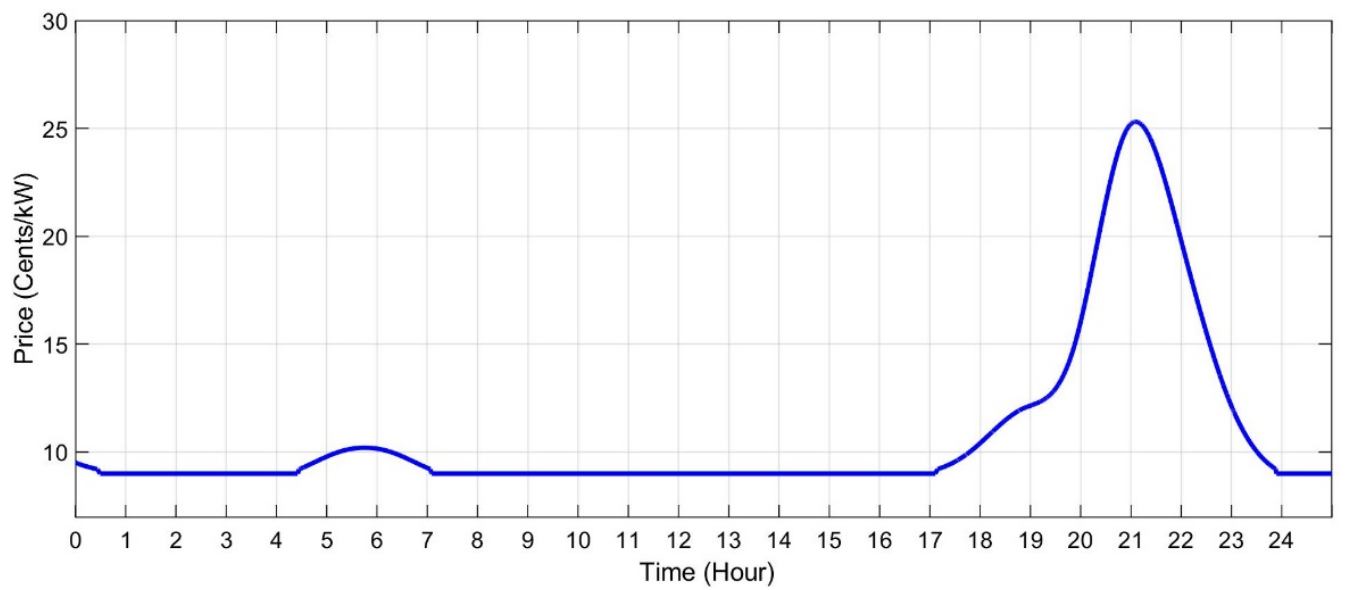

(c)

Figure 15. Linear programing optimization method, (a) power of renewable energy sources, (b) SoC of energy storage system, (c) price

\section{Pricing Patterns}

The proposed work uses the pricing signal for bill calculation (linear programming) because optimization offers more flexibility than other pricing schemes. It is because its value varies every hour according to the consumption of the load. Therefore, scheduling variable load optimization in cost reduction scenarios is easier and efficient, although optimism is an efficient pricing scheme where cost reduction is the main goal. Optimization can create rebound peaks, however, as all users attempt to transfer load within small hours.

The integrated model of linear programming and heuristics is then used to reduce the peak to average (PAR) ratio and energy consumption bill. This hybrid model primarily aims at reducing product usage and PAR costs. Normally, the utility perceives these costs well in advance. The combined heuristics model gives the potential users the flexibility to participate in DR load management schemes. Figure 16 shows the grid price average and Figure 17 shows total grid consumption. 


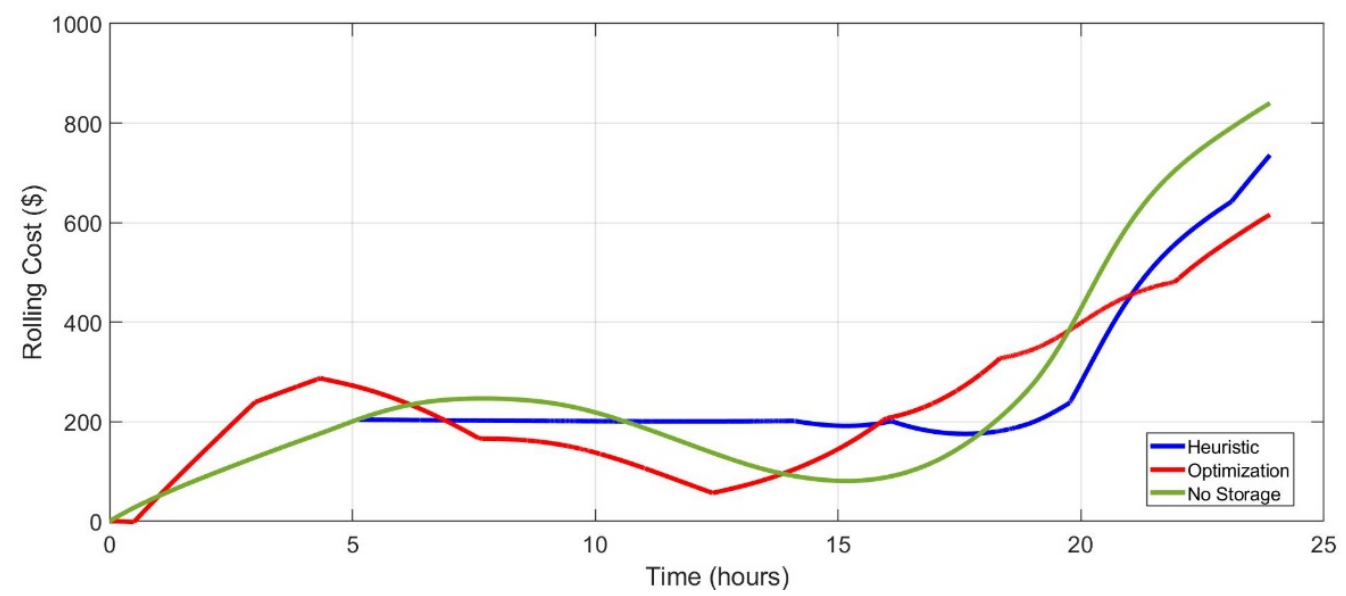

Figure 16. The cumulative of grid cost

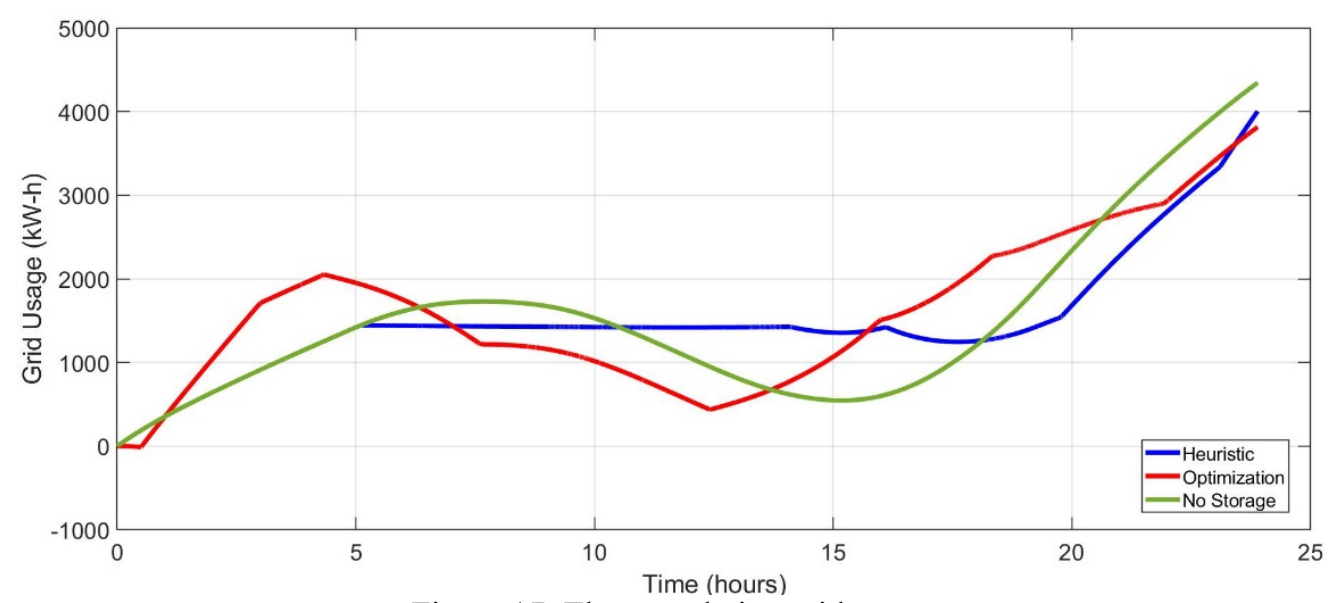

Figure 17. The cumulative grid usage

\section{Conclusion}

In this article, a novel hierarchical energy management strategy was proposed for a multimicro grid system. It was shown in our studies that interconnected micro grids are imposed to different endogenous and exogenous sources of uncertainties that need to be accurately modeled in the problem formulation. The goal of the interconnected micro grid in this paper was to confine uncertainty inside the micro grids network and to minimize the unscheduled power exchange with the main grid considering system cost. This research proposed a two-stage model of home energy management system by considering the uncertainties of load and small-scale renewable energy generation. The first stage included a modified deterministic day-ahead scheduling problem. In this stage, the aggregator requests to control the consumption were fulfilled. Besides, the satisfaction characteristic of the customer was modeled and alongside with the battery degradation cost was considered in the problem. The second stage added a real-time regulation block to the proposed home energy management system. An embedded optimization problem applied to train the controller to maintain the optimality of the solution. The simulation results clearly show that the novel added block yielded up to $95 \%$ success rate to handle the deviations. Moreover, it is observed; by considering the real-time regulation algorithm, the proposed home energy management system can optimize the operating schemes close to the ideal deterministic results. Also, the proposed method provides real-time monitoring and control of demand-side management system. It improves the performance of the system load to the level of distributed energy resource saturation. 


\section{References}

[1]. Bilal Naji Alhasnawi, Basil H. Jasim, Walid Issa, Amjad Anvari-Moghaddam and Frede Blaabjerg "A New Robust Control Strategy for Parallel Operated Inverters in Green Energy Applications", Energies, vol. 13, no. 13, pp. 3480-3500, 2020.

[2]. Q. Xu, J. Xiao, P. Wang, and C. Wen, "A Decentralized Control Strategy for Economic Operation of Autonomous AC, DC, and Hybrid AC/DC microgrids," IEEE Transactions on Energy Conversion, vol. 29, no. 6, pp. 145-164, 2018.

[3]. E. Planas, J. Andreu, J. Garate, I. Martínez, D. Alegría, E. Ibarra, "AC and DC Technology in Microgrids: A Review", Renewable \& Sustainable Energy Reviews, Vol. 43, pp.726$749,2015$.

[4]. F. Martin-Martínez, A. Sanchez-Miralles, M. Rivier, "A literature review of Microgrids: a Functional Layer Based Classification", Renewable \& Sustainable Energy Reviews, Vol 62, pp. 1133-1153, 2016.

[5]. G. Turner, J.P. Kelley, S. Member, C.L. Storm, D.A. Wetz, S. Member, W. Lee, "Design and Active Control of a Microgrid Testbed", IEEE Transaction on Smart Grid, vol.6, pp. 73-81, 2015.

[6]. Leon Ortz, Rogelo Orizodo, Alexandr Agula, Jorg W. Gonz, Gabrel J. Lopz, I. Isac, "Hybrd AC/DC microgrd test system simulaton: grid-connected mode ", Heliyon, Vol. 5, no. 12, pp. 1 - 21, 2019.

[7]. M.H. Andishgar, E. Gholipour, R. allah Hooshmand, "An Overview of Control Approaches of Inverter-Based Microgrids In Islanding Mode of Operation", Renewable \& Sustainable Energy Reviews, vol. 80, pp. 1043-1060, 2017.

[8]. K. Harinadha Reddy, "Performance Analysis of Solar Energy System with Bidirectional Converters and Using Fuzzy Inference Based Modified Inertia PSO Technique", International Journal on Electrical Engineering and Informatics, vol.12, no. 1, 2020.

[9]. C. Delgado, D. Navarro, "Optimal Design of a Hybrid Renewable Energy System", In Proceedings of the 2014 Ninth International Conference on Ecological Vehicles and Renewable Energies (EVER), Monte-Carlo, Monaco, 25-27 March 2014.

[10]. S. Helal, R. Najee, M. Hanna, F. Shaaban, A. Osman, M. Hassan, "An Energy Management System for Hybrid Microgrids In Remote Communities", Canadian Conference on Electrical and Computer Engineering, 2017.

[11]. A. Luna, L. Meng, N. Diaz, M. Graells, J. Vasquez, J. Guerrero, "Online Energy Management Systems for Microgrids: Experimental Validation and Assessment Framework", IEEE Transactions on Power Electronics, vol.33, pp.134-146, 2018.

[12]. M. Abedini, M. Moradi, S. Hosseinian, "Optimal Management of Microgrids Including Renewable Energy Sources Using GPSO-GM Algorithm", Renewable Energy, vol. 56, pp. 45-55, 2016.

[13]. Karima Amara, Toufik Bakir, Ali Malek, Dalila Hocine, El-Bay Bourennane, Arezki Fekik, and Mustapha Zaouia, "An Optimized Steepest Gradient Based Maximum Power Point Tracking for PV Control Systems ", International Journal on Electrical Engineering and Informatics, vol. 11, No. 4, 2019.

[14]. J. Almada, R. Leão, F. Sampaio, B. Barroso, "A Centralized and Heuristic Approach for Energy Management of an AC Microgrid", Renewable and Sustainable Energy Review, vol. 45, pp. 67-87, 2017.

[15]. A. Merabet, A. Tawfique, K. Ibrahim, H. Beguenane, R. Ghias, "Energy Management and Control System for Laboratory Scale Microgrid Based Wind-PV-Battery", IEEE Transactions on Sustainable Energy, vol.8, 2018.

[16]. H. Farzin, M. Firuzabad, M. Aghtaie "Stochastic Energy Management of Microgrids During Unscheduled Islanding Period", IEEE Transactions on Industrial Informatics, vol.13, pp.1079 - 1087, 2019.

[17]. Bilal Naji Alhasnawi, and Basil H. Jasim "A New Coordinated Control of Hybrid Microgrids with Renewable Energy Resources Under Variable Loads and Generation 
Conditions ", Iraqi Journal for Electrical and Electronic Engineering, vol. 16, no.1, pp. 120, 2020.

[18]. Mohammed Ali Tawfeeq, "Optimization of Neural Networks Based on Modified MultiSonar Bat Units Algorithm ", International Journal on Electrical Engineering and Informatics, vol.12, No. 1, 2020.

[19]. B. Tarek, D. Said, and M. Benbouzid, "Maximum Power Point Tracking Control for Photovoltaic System Using Adaptive Neuro-Fuzzy", IEEE, 2013, 8th International Conference and Exhibition on Ecological Vehicles and Renewable Energies (EVER), pp. $1-7,2013$.

[20]. M. Mahdavi, Li Li, J. Zhu and S. Mekhilef, "An Adaptive Neuro Fuzzy Controller for Maximum Power Point Tracking of Photovoltaic Systems", IEEE,2015, TENCON 2015 2015 IEEE Region10 Conference, pp.1-6, 2015.

[21]. M. Villalva, J. Gazoli, E. Ruppert, "Modeling and Circuit-Based Simulation of Photovoltaic Arrays", Brazilian Journal of Power Electronics, Vol. 14, No. 1, pp. 35-45, 2009.

[22]. Bilal Naji Alhasnawi, and Basil H. Jasim "Adaptive Energy Management System for Smart Hybrid Microgrids ", The 3rd Scientific Conference of Electrical and Electronic Engineering Researches (SCEEER) (15-16) JUNE 2020 | BASRAH / IRAQ, pp. 73-85, 2020.

[23]. Salah NECAIBIA, Mounia Samira, Hocine LABAR, Ammar NECAIBIA2, Okba DJELAILIA, and Faycel MERAD1, "Practical Implementation of a Proposed MPPT Control Strategy to Mitigate Inaccurate Responses for Photovoltaic Systems ", International Journal on Electrical Engineering and Informatics, vol.10, no. 4, 2018.

[24]. H. Fathima, K. Palanisamy, "Optimization in Microgrids with Hybrid Energy Systems - a Review". Renewable \& Sustainable Energy Reviews, Vol.45, pp. 431-46, 2015.

[25]. Walid Issa, Suleiman Sharkh, Mohammad Abusara "Hybrid Generators-based AC Microgrid Performance Assessment in Island Mode", IET Power Electronics Vol. 12, Issue: 8, pp. 1973 - 1980, 2019.

[26]. Rashid Al Badwawi ; Walid R. Issa ; Tapas K. Mallick ; Mohammad Abusara, "Supervisory Control for Power Management of an Islanded AC Microgrid Using a Frequency Signalling-Based Fuzzy Logic Controller", IEEE Transactions on Sustainable Energy, Vol. 10 , Issue. 1. pp. 94 - 104, 2019.

[27]. Faris Al-naemi ; Walid Issa ; Asmaiel Ramadan ; Jeremy Hall, "Design and Modelling of Permanent Magnet Fault Current Limiter For Electrical Power Applications ", 2018 53rd International Universities Power Engineering Conference (UPEC), 4-7 Sept. 2018,

[28]. Walid R. M. Issa. Improved Control Strategies for Droop-Controlled Inverter-Based Microgrid, Doctor of Philosophy in Renewable Energy, University of Exeter, 2015. 


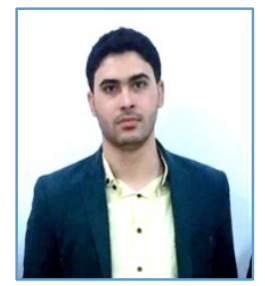

Bilal Naji Alhasnawi was born in Al Samawah, Iraq in 1993. he received the B.S. in Electrical engineering from the University of Kufa, in 2015. he received the M.S. degrees in Electrical engineering from the University of Basrah, in 2018. His research interests Smart Grid Engineering, Control Theory, Renewable Energy Technologies, Electrical Power Engineering, Power Systems Analysis, Power Electronics, Power Converters, Isolated Microgrids, Droop control, hierarchical control, Microgrids Optimization, Energy Management, Photovoltaic, Distributed Generation, Wireless Sensor Network, Information and Communication Technology, and Computer Engineering. He is an Active Reviewer of the IEEE ACCESS.

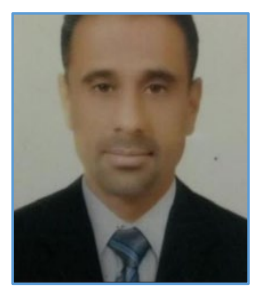

Basil H. Jasim. received the B.Sc and M.Sc degrees in Electrical Engineering and Control \& Computers Engineering from the University of Basrah, Basrah, Iraq in 1995 and 1999 respectively. He also received his $\mathrm{PhD}$ degree in the field of Control and Systems from the Basrah University, Iraq in 2007. His interests Intelligent Control Systems, Robust Control Systems, Microprocessor \& Microcontrollers and Industrial Automation. He currently serves as a co-editor of the Basrah Journal for Engineering Sciences. His research interests include Intelligent Control of Robotics, Computational Intelligence, Chaos \& Nonlinear dynamics, Renewable electrical energy systems, and PLC applications in industrial and engineering education. Dr. Basil is a Senior Member of the IEEE 